\title{
Reported Knowledge, Perceptions, and Behavior of Tourists and North Queensland Residents at Risk of Contact With Jellyfish That Cause the "Irukandji Syndrome"
}

Simone L. Harrison, MPH\&TM, PhD, FACTM; Peter A. Leggat, MD, PhD, FAFPHM; Peter J. Fenner, AM, MB BS, MD, FRCGP; David N. Durrheim, MB ChB, MPH\&TM, DrPH; Anne L. Swinbourne, MPsych(Clin), PhD

From the Anton Breinl Centre, School of Public Health and Tropical Medicine, James Cook University, Townsville, Queensland, Australia (Drs Harrison, Leggat, and Durrheim); Surf Life Saving Australia, Mackay, Queensland, Australia (Dr Fenner); and the School of Psychology, James Cook University, and Tropical Public Health Unit, Queensland Health, Townsville, Queensland, Australia (Dr Swinbourne).

\begin{abstract}
Objective.-To determine the knowledge, beliefs, and behavior of local residents and visitors to North Queensland who may be at risk of contact with "Irukandji" jellyfish.

Methods. - Structured interviews were conducted with 208 ferry passengers ( $92.9 \%$ response) traveling between Magnetic Island and Townsville $\left(19^{\circ} \mathrm{S}\right)$.

Results. - A total of $88.1 \%$ of the locals, $69.8 \%$ of the domestic tourists, and $34 \%$ of the international tourists knew what an Irukandji was $(P<.001)$. Half of the international tourists, $20 \%$ of the domestic tourists, and $3.9 \%$ of the locals with this knowledge incorrectly assumed it was safe to swim inside stinger-resistant enclosures or were unsure $(P<.001)$. Visitors to Magnetic Island who had swum or intended to swim in the sea $(47 \%)$ knew less about Irukandji than other visitors $(P=.05)$. Only $42.3 \%$ of the respondents realized that Irukandji posed a risk to swimmers on the outer reefs, and only $33.1 \%$ knew that Irukandji were also found outside North Queensland.

Conclusions. - International tourists had little knowledge about Irukandji. Thus, accurate educational messages may need to be targeted at this group. Offshore water sport and reef tour operators should be encouraged to provide clients with protective clothing to minimize the risk of stings. A coordinated educational response across northern Australia may be necessary to inform the public about both the box jellyfish (Chironex fleckeri) and Irukandji.
\end{abstract}

Key words: Irukandji syndrome, bites and stings, knowledge, attitudes, adverse effects

\section{Introduction}

Envenomation by the small cubozoan (box) jellyfish $\mathrm{Ca}$ rukia barnesi and possibly other undescribed carybdeid jellyfish $^{1}$ can trigger a series of severe symptoms known as

The authors are not aware of any competing interests. The funding bodies who provided financial support did not control or influence the content of the manuscript or the decision to submit the final manuscript for publication. All authors contributed to 1) the design, acquisition, or analysis of the data, and 2) the preparation of the manuscript. All authors have approved the final version and are prepared to take public responsibility for the article.

Corresponding author: Peter Leggat, MD, PhD, FAFPHM, School of Public Health and Tropical Medicine, James Cook University, Townsville, Queensland 4811, Australia (e-mail: peter.leggat@jcu. edu.au). the "Irukandji syndrome" usually within 5 to 45 minutes of being stung..$^{1-4}$ These symptoms may be life threatening, with 2 deaths having occurred in Australia. ${ }^{5}$ However, unlike its larger relative the box jellyfish, Chironex fleckeri, whose sting causes large welts on the skin and has a direct cardiotoxic effect, contact with Irukandji generally produces a mild skin irritation and may initially be overlooked as the cause of the severe systemic symptoms. ${ }^{1-3}$ Studies of venom extracted from $C$ barnesi indicate that it acts as a sodium channel agonist causing a massive release of catecholamines, with noradrenaline occurring in the highest concentrations. ${ }^{6}$

C barnesi is generally found close to Cairns $\left(16^{\circ} 44^{\prime} \mathrm{S}\right)$ in North Queensland; ${ }^{2}$ however, Irukandji syndrome has 


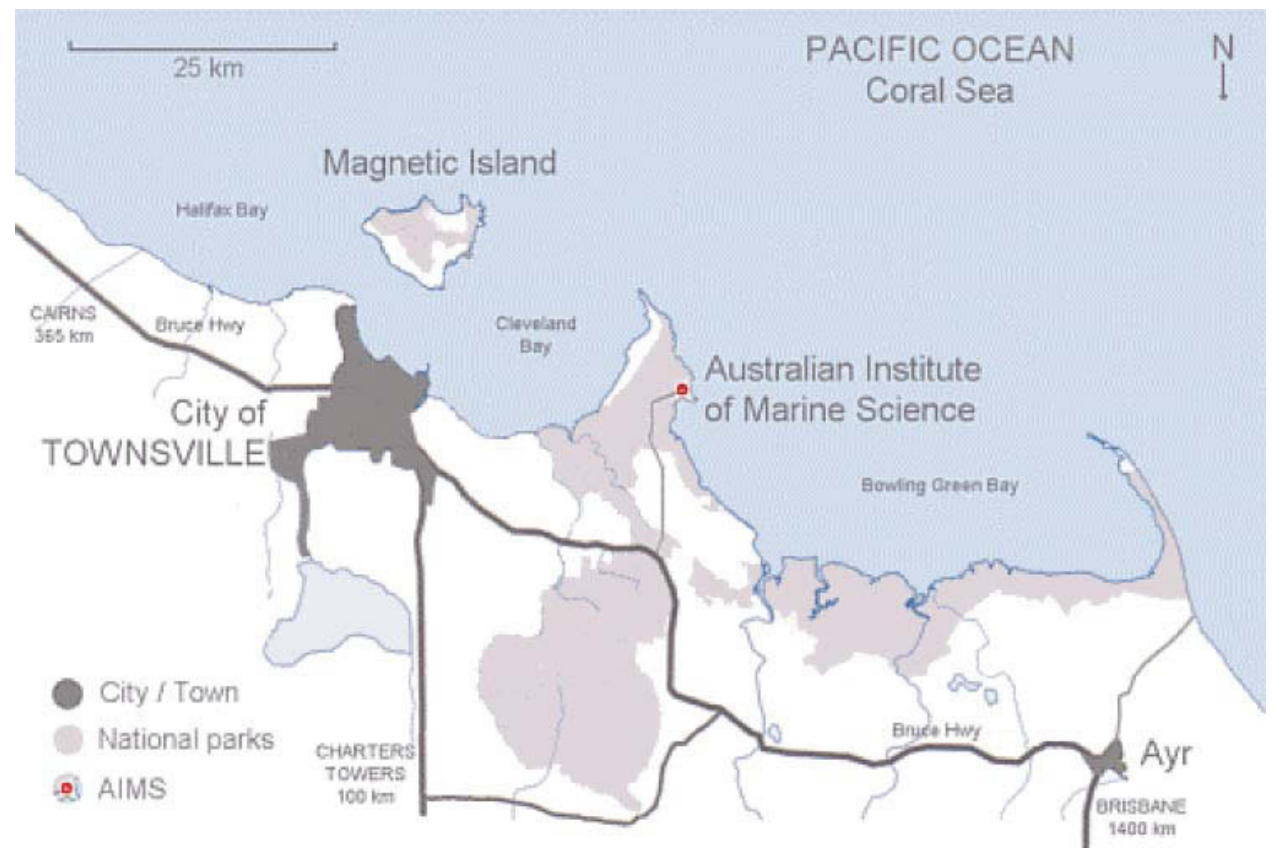

Map of Magnetic Island showing its relation to Townsville, North Queensland. Map courtesy of the Australian Institute of Marine Science. Available at: http:/www.aims.gov.au/pages/about/environs/whereis-aims-tvl.html. Accessed August $31,2003$.

been reported as far south as Bundaberg $\left(24^{\circ} 45^{\prime} \mathrm{S}\right)^{7}$ and as far west as Broome $\left(17^{\circ} 58^{\prime} \mathrm{S}\right)^{1}$ and also occurs in the Northern Territory. ${ }^{4,7}$ The number and severity of Irukandji stings vary considerably from year to year, and cases have been reported in all months other than July and August. ${ }^{4}$

In Australia, during the 2001-02 summer, there were unusually large numbers of Irukandji stings over a wide stretch of coastline. In addition, the first 2 deaths associated with the Irukandji syndrome occurred in tropical Queensland early in 2002.5 Because both of the victims were international visitors, these fatalities resulted in considerable public and scientific attention. Both male patients died following a severe intracranial hemorrhage secondary to extreme hypertension after envenomation by a jellyfish. ${ }^{5}$

Despite the recent publicity about severe jellyfish stings in tropical Australian waters and calls to increase public awareness of the dangers of these marine creatures, little is known about the knowledge, perceptions, and behavior of the tourists and residents who are at risk of coming into contact with these jellyfish. This study was designed to investigate the knowledge, beliefs, and behavior of local residents and visitors to Townsville, North Queensland, an area where there is a risk of contact with Irukandji jellyfish. The findings presented may assist in the development of targeted educational strategies and enable primary care practitioners to assist in preventing stings through patient education.

\section{Methods}

Consent was obtained from the Directors of Sunferries Pty Ltd to survey ferry passengers traveling between the Townsville mainland $\left(19^{\circ} \mathrm{S}\right)$ and Magnetic Island (see Figure) between 8:40 AM and 5:20 PM on one Saturday in April 2002. At the beginning of each journey, a crewmember made a microphone announcement to introduce the researchers, indicating only that they were conducting a general travel survey. These ferries constitute the only means of traveling to and from Magnetic Island, except for occasional private launches and vehicular ferries.

At the beginning of each journey, the team of 9 trained interviewers spread out across the 3 decks of the vessel. Each interviewer approached the first passengers who sat down in their "section" of the boat. A written information sheet was provided, and verbal consent was obtained from all participants. Care was taken not to mention jellyfish, Irukandji, or stingers either during the announcement or by the interviewer before asking the passengers if they knew what an Irukandji was.

A structured interview schedule was used, and the interviewers were careful to position themselves such that the interviewee was not within earshot of other interviewers. The number of nonrespondents was recorded to determine the response rate.

Prior to conducting the research, ethical approval was granted by the Human Ethics Sub-Committee of the James Cook University. 


\section{STATISTICAL ANALYSIS}

Participants who claimed to know what an Irukandji was were asked to answer 9 knowledge questions about Irukandji (8 true/false/unsure questions and 1 multiple choice question). People who did not know what an Irukandji was were not asked these questions. Individual knowledge scores were generated by scoring one point for each correct answer and zero for each incorrect or unsure response, up to a maximum possible score of 9 . A score of zero was recorded for all people who did not know what an Irukandji was. All participants who were leaving the island were asked if they had swum in the ocean while on Magnetic Island and, if so, whether they had stayed within the stinger net enclosures. Likewise, all island-bound passengers were asked whether they intended to swim in the ocean. All of the tourists who were interviewed were asked an additional 2 yes/no questions to determine whether they were aware of the risks associated with 1) the large box jellyfish (Chiro$n e x)$, or 2) Irukandji before they arrived in North Queensland.

Categorical variables have been expressed as proportions, and continuous variables have been described as median values with interquartile ranges (IQR). Bivariate analysis used $\chi^{2}$ tests (chi-square tests), Fisher exact tests, and nonparametric Kruskal-Wallis tests as appropriate. Data analysis was performed using SPSS V6.3 for Windows.

\section{Results}

Of the 224 passengers who were approached, $92.9 \%$ ( $n$ $=208$ ) agreed to participate. Nine nonparticipants were male, and 7 were female. Nonparticipants included some passengers who could not speak English.

A similar proportion of local residents and tourists were surveyed, and the ratio of domestic to international tourists was approximately equal. Ages ranged from 9 to 78 years, with a median of 31.5 years (Table 1).

About three fourths $(72.1 \%)$ of the participants claimed to know what an Irukandji was. An open-ended question confirmed that at least 147 of these 150 participants knew that an Irukandji is a jellyfish/marine stinger.

More local residents $(88.1 \%)$ than tourists $(51.1 \%)$ knew what an Irukandji was $\left(\chi^{2}, P<.001\right)$. Among the locals, fewer mainland residents (80.6\%) than Magnetic Island residents $(100 \%)$ had heard of Irukandji (Fisher exact test, $P<.001)$. When tourists were compared by place of origin, it was evident that more domestic $(69.8 \%)$ than international tourists $(34 \%)$ knew what an Irukandji was $\left(\chi^{2}, P<.001\right)$. No age differences were detected between locals who knew what an Irukandji was and locals who did not know $\left(\chi^{2}, P=.149\right)$. In contrast, tourists who knew what an Irukandji was were older (median, 33 years [IQR 23, 48.5]) than those who did not know (median, 24.5 years [IQR 20.25, 39.25]; $\left.\chi^{2}, P=.029\right)$. However, stratification showed that this difference was explained by whether they were international or domestic tourists.

Overall, a similar proportion of males and females knew what an Irukandji was $\left(\chi^{2}, P=.142\right)$. There was no evidence of a gender-based knowledge difference among tourists $\left(\chi^{2}, P=.746\right)$. Among locals, a higher proportion of males than females knew what an Irukandji was $\left(\chi^{2}, P=.032\right)$.

The majority of locals knew that stinger-resistant enclosures would not prevent the entry of Irukandji, while significantly fewer tourists $(80 \%$ of domestic and $50 \%$ of international tourists) were aware of this fact (Table 2).

The median knowledge score was 5. International tourists knew least about Irukandji (median, 0 [IQR 0 , 4]), followed by domestic tourists (median, 6 [IQR 0 , 7]), mainland residents (median, 6 [IQR 4, 7]), and Magnetic Island residents (median, 6 [IQR 5, 7.25]; KruskalWallis test, $P=0<.001)$. Knowledge scores did not differ by gender either overall (Kruskal-Wallis test, $P=$ .804 ) or within residential groupings (all Kruskal-Wallis tests, $P>.26$ ).

Only half of the domestic tourists and just more than one third $(36.2 \%)$ of the international tourists surveyed were aware of the risks associated with Irukandji prior to their arrival in North Queensland. In contrast, most $(85.7 \%)$ tourists $(93.3 \%$ of domestic tourists and $80.9 \%$ of international tourists) stated that they were familiar with the risks associated with the large box jellyfish prior to their arrival in the region, although specific questions were not asked regarding their knowledge of box jellyfish venom.

Of the respondents who believed they knew what an Irukandji was, just less than one fourth $(22.8 \%)$ had no idea what time of year they were found in the sea off North Queensland. More than half of the 115 respondents who provided a time of year believed that Irukandji were found off North Queensland only between November and April.

Almost two thirds (63.7\%) of the visitors to Magnetic Island (including tourists and mainland locals) who knew what an Irukandji was indicated that the possibility of encountering an Irukandji had influenced their participation in water activities. Of the 74 who explained their answer, most $(87.8 \%)$ said they avoided swimming in the ocean, and a few $(9.5 \%)$ said they swam in the sea only when wearing a lycra suit.

Nearly half (47\%) of the visitors to Magnetic Island 
Table 1. Demographic characteristics of participants*

\begin{tabular}{|c|c|c|c|c|c|c|c|}
\hline & All & Locals & & & & Tourists & \\
\hline \multirow[t]{12}{*}{ Residential status $(n=208)$} & \multirow[t]{12}{*}{$208(100 \%)$} & \multicolumn{2}{|c|}{$118(56.7 \%)$} & \multicolumn{4}{|c|}{$90(43.3 \%)$} \\
\hline & & \multirow{3}{*}{$\begin{array}{l}\text { Magnetic Island } \\
\text { Mainland Townsville }\end{array}$} & \multirow{3}{*}{$\begin{array}{l}72(61 \%) \\
46(39 \%)\end{array}$} & \multicolumn{2}{|c|}{$\begin{array}{c}\text { Domestic } \\
43(20.7 \%)\end{array}$} & \multicolumn{2}{|l|}{$\begin{array}{c}\text { International } \\
47(22.6 \%)\end{array}$} \\
\hline & & & & Queensland & $24(55.8 \%)$ & New Zealand & $2(4.3 \%)$ \\
\hline & & & & Northern Territory & $1(2.3 \%)$ & United Kingdom & $23(48.9 \%)$ \\
\hline & & & & NSW & $10(23.3 \%)$ & Ireland & $4(8.5 \%)$ \\
\hline & & & & $\mathrm{ACT}$ & $1(2.3 \%)$ & South-East Asia & $2(4.3 \%)$ \\
\hline & & & & Victoria & $6(14 \%)$ & United States and Canada & $7(14.9 \%)$ \\
\hline & & & & South Australia & 0 & Austria & $1(2.1 \%)$ \\
\hline & & & & Western Australia & $1(2.3 \%)$ & Netherlands & $2(4.3 \%)$ \\
\hline & & & & Tasmania & 0 & Sweden & $4(8.5 \%)$ \\
\hline & & & & & & Switzerland & $1(2.1 \%)$ \\
\hline & & & & & & Italy & $1(2.1 \%)$ \\
\hline Gender (male:female ratio) $(n=207) \dagger$ & $1: 1.09$ & $1: 1.07$ & & $1: 0.75$ & & $1: 1.61$ & \\
\hline Age, y (median, IQR) $(n=198) \dagger$ & 31.5 [IQR 23, 48] & 35 [IQR 24, & & $45[\mathrm{IQR} 31.5$ & , 55.5] & $23[$ IQR 21, 2 & \\
\hline \multicolumn{8}{|l|}{ Holiday expenditure per person/d } \\
\hline Australian $\$$ (median, IQR) $(n=90)$ & $\mathrm{n} / \mathrm{a}$ & \multicolumn{2}{|l|}{$\mathrm{n} / \mathrm{a}$} & \multicolumn{2}{|c|}{$\$ 62.50[\mathrm{IQR} \$ 35.70, \$ 175]$} & \multicolumn{2}{|c|}{$\$ 50[\mathrm{IQR} \$ 25, \$ 50]$} \\
\hline
\end{tabular}

*IQR indicates interquartile range; NSW, New South Wales; and ACT, Australian Capital Territory.

†Gender not recorded for 1 participant.

\$Age withheld by 10 participants. 
Table 2. Answers to Irukandji knowledge questions by subjects who claimed to know what an Irukandji is

\begin{tabular}{|c|c|c|c|c|c|}
\hline & $\mathrm{n}$ & Correct $(\%)$ & Incorrect $(\%)$ & Unsure (\%) & $\mathrm{P}$-value \\
\hline \multicolumn{6}{|c|}{ You can tell when it is risky to swim in the ocean because you can see Irukandji in the water?* } \\
\hline Total & $149+$ & $131(87.9)$ & $9(6)$ & $9(6)$ & \\
\hline Locals & 103 & $92(89.3)$ & $7(6.8)$ & $4(3.9)$ & \\
\hline Tourists & 46 & $39(84.8)$ & $2(4.3)$ & $5(10.9)$ & $0.432 \S$ \\
\hline \multicolumn{6}{|c|}{ Irukandji are generally only a problem close to the shore on windy days?* } \\
\hline Total & 149 & $101(67.8)$ & $14(9.4)$ & $34(22.8)$ & \\
\hline Locals & 103 & $72(69.9)$ & $10(9.7)$ & $21(20.4)$ & \\
\hline Tourists & 46 & $29(63)$ & $4(8.7)$ & $13(28.3)$ & $0.408 \S$ \\
\hline \multicolumn{6}{|c|}{ You are safe from Irukandji if you swim within a stinger net enclosure?* } \\
\hline Total & 149 & $131(87.9)$ & $12(8.1)$ & $6(4)$ & \\
\hline Locals & 103 & $99(96.1)$ & $3(2.9)$ & $1(1)$ & $<0.001 \S$ \\
\hline Tourists & 46 & $32(69.6)$ & $9(19.6)$ & $5(10.9)$ & $<0.001 \|$ \\
\hline \multicolumn{6}{|c|}{ Contact with an Irukandji can be life threatening $\dagger$} \\
\hline Total & 149 & $141(94.6)$ & $5(3.4)$ & $3(2)$ & \\
\hline Locals & 103 & $98(95.1)$ & $4(3.9)$ & $1(1)$ & \\
\hline Tourists & 46 & $43(93.5)$ & $1(2.2)$ & $2(4.3)$ & 0.7039 \\
\hline \multicolumn{6}{|c|}{ Contact with an Irukandji is usually extremely painful? $\dagger$} \\
\hline Total & 149 & $126(84.6)$ & $13(8.7)$ & $10(6.7)$ & \\
\hline Locals & 103 & $87(84.5)$ & $11(10.7)$ & $5(4.9)$ & \\
\hline Tourists & 46 & $39(84.8)$ & $2(4.3)$ & $5(10.9)$ & $0.961 \S$ \\
\hline \multicolumn{6}{|c|}{ Only people with a preexisting heart condition are at risk of dying after coming into contact with an Irukandji?* } \\
\hline Total & 149 & $112(75.2)$ & $17(11.4)$ & $20(13.4)$ & \\
\hline Locals & 103 & $80(77.7)$ & $12(11.7)$ & $11(10.7)$ & \\
\hline Tourists & 46 & $32(69.6)$ & $5(10.9)$ & $9(19.6)$ & $0.290 \S$ \\
\hline \multicolumn{6}{|c|}{ You are safe from Irukandji when swimming on the outer Great Barrier Reef?* } \\
\hline Total & 149 & $63(42.3)$ & $34(22.8)$ & $52(34.9)$ & \\
\hline Locals & 103 & $47(45.6)$ & $23(22.3)$ & $33(32)$ & \\
\hline Tourists & 46 & $16(34.8)$ & $11(23.9)$ & $19(41.3)$ & $0.216 \S$ \\
\hline \multicolumn{6}{|c|}{ Irukandji are only found in North Queensland?* } \\
\hline Total & 148 & $49(33.1)$ & $35(23.6)$ & $64(43.2)$ & \\
\hline Locals & 103 & $37(35.0)$ & $20(19.4)$ & $46(44.7)$ & \\
\hline Tourists & 45 & $12(26.7)$ & $15(33.3)$ & $18(40)$ & $0.271 \S$ \\
\hline \multicolumn{6}{|c|}{ How large is an average Irukandji across its body? } \\
\hline Total & 149 & $52(34.9)$ & $94(63.1)$ & $3(2)$ & \\
\hline Locals & 103 & $33(32)$ & $68(66)$ & $2(2)$ & \\
\hline Tourists & 46 & $19(41.3)$ & $26(56.5)$ & $1(2.2)$ & $0.273 \S$ \\
\hline
\end{tabular}

*False statement.

$\dagger$ True statement.

$\$ 149$ of 150 who claimed to know what an Irukandji was answered the knowledge questions (1 declined to answer).

$\S$ Chi-square test comparing proportion of tourists and locals who provided correct answers to knowledge questions (correct vs. incorrect/ unsure).

qFisher exact test used to compare proportion of tourists and locals who provided correct answers to knowledge questions (correct vs incorrect/ unsure).

||Chi-square test comparing proportion of locals, domestic tourists, and international tourists who provided correct answers to knowledge questions (correct vs incorrect/unsure). 
reported that they had swum (passengers returning to the mainland) or intended to swim (arrivals) in the sea while on Magnetic Island, and a few $(10.2 \%)$ were undecided. Similar proportions of residents $(43.5 \%)$, domestic tourists $(38.1 \%)$, and international tourists $(45.7 \%)$ said they had swum or intended to swim in the sea $\left(\chi^{2}, P=.936\right)$. This self-reported risk-taking behavior did not vary by age (Kruskal-Wallis test, $P=.331)$ or gender $\left(\chi^{2}, P=\right.$ .793). However, risk takers tended to be less well informed about Irukandji (median knowledge score, 4 [IQR 0,6]) than those who said they did not swim (median, 5.5 [IQR 0, 7]) and arriving passengers who were still undecided (median, 4.5 [IQR 0, 6]; Kruskal-Wallis test, $P=.05)$. Almost two thirds (65.7\% of 67) of the visitors surveyed who had swum or planned to swim in the sea off Magnetic Island chose to swim inside a stinger-resistant enclosure.

\section{Discussion}

Recent severe Irukandji jellyfish stings in North Queensland and the first 2 deaths associated with the Irukandji syndrome ${ }^{5}$ have led to calls for increased public awareness of the dangers posed by these marine creatures. To our knowledge, this is the first study investigating the knowledge, perceptions, and behavior of tourists and local residents at risk of coming into contact with the jellyfish that cause the Irukandji syndrome. An excellent response rate was achieved through the use of interviews. One of the major limitations of interviews is that what people report may differ from what they actually do; however, this was overcome as much as possible through the use of selected knowledge-based questions.

Although this study was conducted during a time of extensive media coverage about the jellyfish that cause the Irukandji syndrome, only about three fourths (72\%) of the ferry passengers surveyed knew what an Irukandji was. Most of these people were aware that an Irukandji sting could be life threatening and extremely painful and that it was incorrect to assume that visual inspection of the ocean for Irukandji would allow accurate assessments of whether it was safe to swim.

International tourists knew significantly less about Irukandji than domestic tourists and residents, indicating that brochures and other educational resources should be designed with this group in mind. In-flight videos with subtitles and multilingual brochures or in-flight magazine articles placed in seat pockets on inbound international flights could be used to educate international visitors about the risks associated with Irukandji and the strategies to reduce the likelihood of being stung (eg, use of personal protective clothing such as lycra suits; tips on safer swimming venues; explanation of the in- effectiveness of stinger-resistant enclosures in preventing the entry of Irukandji). In-flight magazines of international airlines servicing Australia have been underutilized as a means of providing destination-specific health and safety advice for travelers. ${ }^{8}$ A similar approach could be used on domestic flights, buses, and ferries headed to destinations where water activities are popular and Irukandji are prevalent. Written materials could also be distributed through car hire companies, hotels, and backpacker hostels in addition to travel agencies, travel medicine clinics, and general practice surgeries. Travelers' information evenings may also be useful in helping to inform intending and current travelers about potential hazards. ${ }^{9}$ A need for more information on health and safety for tourists from abroad has been demonstrated previously. ${ }^{10}$

It may be that public health and travel health providers are more reliably placed to educate the public and travelers, respectively, than the tourism and travel industry, which may not have the expertise to be responsible for this task. This needs to be further investigated. General practitioners and other health professionals who may encounter a patient with this problem could be provided with a treatment protocol.

A considerable proportion of the residents and tourists who knew what an Irukandji was did not realize that Irukandji are also found outside North Queensland. Since the jellyfish that cause the Irukandji syndrome are also found in the Northern Territory, ${ }^{4,7}$ North Western Australia, ${ }^{1}$ and sometimes also along the Capricorn Coast, ${ }^{7}$ it would be sensible to coordinate an educational response that extends across northern Australia.

Less than half of the residents and approximately one third of the tourists who knew what an Irukandji was realized that they could be stung by Irukandji while swimming on the outer Great Barrier Reef. Reef tour/ charter operators should warn passengers about Irukandji, particularly during periods of increased Irukandji activity. If reef tour operators and offshore water sports companies provide factual information, which would allow clients to make informed decisions about swimming, and maintain signed informed consent forms, their risk of future litigation in the unfortunate event that a passenger is stung will be minimized. Because the use of wetsuits and/or lycra stinger suits reduces the risk of being stung while diving, snorkeling, or participating in other offshore water sports, tourism operators should be encouraged to provide these items while informing clients that Irukandji may still sting small, exposed areas, including the lips, resulting in Irukandji syndrome (P.J.F., oral communication).

Ferry companies and reef tour/charter operators should be provided with factual information kits about 
Irukandji syndrome. Kits should include appropriate advice on first aid treatment and an emergency telephone number for medical advice. First aid kits should be mandatory and, as improved first aid treatments to control severe hypertension associated with the Irukandji syndrome become available, they should also be included.

Unfortunately, the mesh of stinger-resistant enclosures is broad enough to allow Irukandji jellyfish through (D. Close, unpublished data, 2002), and a large proportion of stings occur within these enclosures. ${ }^{11,12}$ The majority of residents who participated were aware that stingerresistant enclosures would not prevent the entry of Irukandji, but many tourists, particularly those from abroad, were unaware of this fact. This false sense of security may be the result of a misconception about Irukandji size, with many respondents believing it to be larger than its actual $2.5-\mathrm{mm}$ bell diameter. ${ }^{2}$ Specific authorities elect to close beaches whenever 3 days of northerly winds are followed by an afternoon high tide, although this predictive model remains unproven. Tour operators and ferry companies should be encouraged to warn passengers that, while stinger-resistant enclosures prevent the entry of the box jellyfish, they do not protect swimmers from Irukandji. Swimming in resort pools should be encouraged during periods of peak Irukandji activity until safer swimming enclosures can be designed, tested, and implemented.

Routine media coverage did not appear to reach or influence many of the respondents of this survey. Radio and television warnings, presented in a manner similar to UV index forecasts aimed at preventing sunburn, should be considered for cautioning the public when there is increased Irukandji activity and particularly following a confirmed sting. This information should also be disseminated immediately to lifeguards for issuing local warnings, as it is essential that swimmers avoid the ocean once an Irukandji sting has been confirmed at a particular beach, because Irukandji often occur in swarms.

This research demonstrates that better knowledge about Irukandji may be associated with reported safer behavior, although the behavior was not directly observed. The study also suggests that well-designed targeted educational strategies may reduce risk behaviors among poorly informed groups. Ideally, this study should be repeated in other endemic areas that are perceived to be at higher risk (eg, Cairns, Whitsunday Islands) to confirm these findings, once funding becomes available. This would also provide additional opportunities to validate the questions chosen for the highly structured interviews.

Because most tourists participating in this survey were aware of the risks associated with the box jellyfish
(C fleckeri) before arriving in North Queensland, educational strategies that have been used to raise public awareness about the box jellyfish may provide a suitable model for educating the public about Irukandji. Further studies should include more questions about the box jellyfish in order to test this hypothesis.

\section{Acknowledgments}

We thank the Directors of Sunferries Pty Ltd and their staff for allowing us to access their vessels to interview passengers and the interviewers, Daniel Wronski, Ben Klein, David Gitsham, Judy Woosnam, Torres Woolley, Margaret Glasby, Rachel Fuller, and Virginia MacDonald, who assisted one of us (S.L.H.) in collecting these data. This study was funded in part by the Anton Breinl Centre, James Cook University, and the Thyne-Reid Education Trust No. 1.

\section{References}

1. Kinsey B. Barnes on Box Jellyfish. Townsville: James Cook University of North Queensland; 1986.

2. Barnes JH. Cause and effect in Irukandji stingings. Med J Aust. 1964;1:897-904.

3. Fenner PJ, Williamson J, Callanan VI, Audley I. Further understanding of, and a new treatment for 'Irukandji' ( $\mathrm{Ca}$ rukia barnesi) stings. Med J Aust. 1986;145:569-574.

4. Fenner PJ, Harrison SL. Irukandji and Chironex fleckeri jellyfish envenomation in tropical Australia. Wilderness Environ Med. 2000;11:233-240.

5. Fenner PJ, Hadok J. Fatal envenomation by Irukandji jellyfish. Med J Aust. 2002;177:362-363.

6. Tibballs J, Hawdon GM, Winkel KD. Mechanism of cardiac failure in Irukandji syndrome and first aid treatment for stings. Anaesth Intensive Care. 2001;29:552.

7. Currie B. Box-jellyfish - an update from the Northern Territory and the NT Chironex fleckeri treatment protocol. Northern Territory Dis Control Bull. 2000;7:7-8.

8. Leggat PA. Travel health advice provided by inflight magazines of international airlines in Australia. J Travel Med. 1997;4:102-103.

9. Leggat PA. Health advice provided to hostelers from Australia: influence of a travelers' information evening. $J$ Travel Med. 2002;9:24-28.

10. Peach HG, Bath NE. Health and safety problems and lack of information among international visitors backpacking through North Queensland. J Travel Med. 2000;7:234-238.

11. Fenner PJ, Carney I. The Irukandji syndrome: a devastating syndrome caused by a north Australian jellyfish. Aust Fam Physician. 1999;28:1131-1137.

12. Little M, Mulcahy RF. A year's experience of Irukandji envenomation in far north Queensland. Med J Aust. 1998; 169:638-641. 